\title{
The relationship between cognitive and emotional representations of peripheral neuropathy and incident diabetes-related foot ulceration
}

\author{
Byron Perrin ${ }^{1,2,5^{*}}$, Hal Swerissen ${ }^{3}$, Craig Payne Pa $^{2,4}$ \\ From Australasian Podiatry Council Conference 2011 \\ Melbourne, Australia. 26-29 April 2011
}

\section{Background}

The common sense model of illness (CSM) has been shown to be a useful model to help understand the psychological influences on diabetes-related behaviour and health outcomes. Using the CSM, the aim of this study was to investigate the relationship between cognitive and emotional representations of peripheral neuropathy and diabetes-related foot ulceration in adults with diabetes.

\section{Methods}

One-hundred and twenty-one people with diabetes and peripheral neuropathy were recruited into this one-year prospective cohort study. At baseline, the participants completed two questionnaires- the Patients' Interpretation of Neuropathy questionnaire and a short questionnaire asking about preventative foot-care behaviour. Basic diabetes and demographic information was also collected. Sequential logistic regression was used to investigate the influence of cognitive and emotional representations of peripheral neuropathy as measured by the PIN and the development of incident foot ulceration.

\section{Results}

One-hundred and seventeen participants completed the study. The incidence of new foot ulceration was $34.2 \%$. Only two statistically significant independent risk factors for foot ulceration were detected: prior history of foot ulceration $(\mathrm{OR}=3.1 ; 95 \% \mathrm{CI}: 1.16-8.18 ; \mathrm{p}=.024)$ and

severity of neuropathy $(\mathrm{OR}=1.1 ; 95 \% \mathrm{CI}: 1.00-1.15$; $\mathrm{p}=.047)$.

\section{Conclusions}

A consistent association between cognitive and emotional representations of peripheral neuropathy and incident foot pathology was not found. If the CSM is to be clinically useful for people with diabetes and peripheral neuropathy the mediational role of preventative footcare behaviour should be further investigated.

\section{Author details}

'La Trobe Rural Health School, La Trobe University, Bendigo, Victoria, 3550, Australia. ${ }^{2}$ Musculoskeletal Research Centre, La Trobe University, Bundoora, Victoria, 3086, Australia. ${ }^{3}$ Faculty of Health Sciences, La Trobe University, Bundoora, Victoria, 3086, Australia. ${ }^{4}$ Department of Podiatry, La Trobe University. Bundoora, Victoria, 3086, Australia. ${ }^{5}$ Bendigo Health, Bendigo, Victoria, 3550, Australia.

Published: 20 May 2011

doi:10.1186/1757-1146-4-S1-O37

Cite this article as: Perrin et al:: The relationship between cognitive and emotional representations of peripheral neuropathy and incident

diabetes-related foot ulceration. Journal of Foot and Ankle Research 2011 4(Suppl 1):037.

\footnotetext{
* Correspondence: b.perrin@latrobe.edu.au

'La Trobe Rural Health School, La Trobe University, Bendigo, Victoria, 3550,

Australia

Full list of author information is available at the end of the article
}

(c) 2011 Perrin et al; licensee BioMed Central Ltd. This is an open access article distributed under the terms of the Creative Commons 